MIDAS

Museus e estudos interdisciplinares

$9 \mid 2018$

Varia

\title{
Personas y patrimonios: análisis del contenido de textos que abordan los vínculos identitarios
}

People and heritage: content analysis of texts that address identity links

\section{Olaia Fontal Merillas, Inmaculada Sánchez-Macías e Jesús Cepeda Ortega}

\section{OpenEdition}

\section{Journals}

\section{Edição electrónica}

URL: http://journals.openedition.org/midas/1474

DOI: $10.4000 /$ midas. 1474

ISSN: 2182-9543

\section{Editora:}

Alice Semedo, Paulo Simões Rodrigues, Pedro Casaleiro, Raquel Henriques da Silva, Ana Carvalho

\section{Refêrencia eletrónica}

Olaia Fontal Merillas, Inmaculada Sánchez-Macías e Jesús Cepeda Ortega, « Personas y patrimonios: análisis del contenido de textos que abordan los vínculos identitarios », MIDAS [Online], 9 | 2018, posto online no dia 12 novembro 2018, consultado no dia 19 abril 2019. URL : http:// journals.openedition.org/midas/1474 ; DOI : 10.4000/midas.1474

Este documento foi criado de forma automática no dia 19 Abril 2019.

\section{c) (1)(2)}

Midas is licensed under a Creative Commons Attribution-NonCommercial-ShareAlike 3.0 International License 


\section{Personas y patrimonios: análisis del contenido de textos que abordan los vínculos identitarios}

People and heritage: content analysis of texts that address identity links

Olaia Fontal Merillas, Inmaculada Sánchez-Macías e Jesús Cepeda
Ortega

\section{NOTA DO EDITOR}

Artigo recebido a 08.06.2017

Aprovado para publicação a 11.01.2018

\section{El patrimonio como vínculo}

1 Hemos acotado el concepto patrimonio y el ámbito de aplicación del adjetivo "patrimonial" en diversas publicaciones (Fontal 2003; 2008; 2012; 2013) y, en este proceso de reflexión, hemos podido detectar algunas de las sustancias esenciales que pueden definir el concepto patrimonio y, por extensión, el adjetivo patrimonial. Para comprender tanto ese concepto, como su adjetivación y también sus usos, proponemos concebir - a modo de metáfora - el patrimonio como un perfume cuyo aroma produce un efecto embriagador en quien lo cata; algo así como un halo de aceptación, de agrado, de gran elegancia y finura. Un perfume que a menudo se utiliza para producir ese efecto cautivador - intencionalmente o en la inconsciencia que producen sus aromas - y con el que se pretende, en ocasiones, camuflar otros olores quizá menos agradables.

2 El patrimonio pertenece a las personas, que son sus creadoras, herederas, legatarias, transmisoras, etc. En realidad, podemos dar un paso más y suponer que el patrimonio es inseparable, precisamente, de esas personas, porque establece con ellas vínculos de propiedad, pertenencia, transmisión, selección, valorización y, todo ello, no puede 
hacerse sin personas pero tampoco tiene sentido que se haga si no es para personas. El vínculo es, en sí mismo, el origen de lo patrimonial (Brantefors 2015). Así pues, hablar de patrimonio implica concebir la relación de individuos y grupos con elementos materiales, inmateriales y espirituales. El acento se sitúa, de este modo, en una relación y no en un bien; ahí está la clave de lo patrimonial, el alma del perfume. Si sólo entendemos que el patrimonio son esos bienes (obras de arte, lugares, sitios, costumbres...), estaremos ignorando una de las verdaderas claves del patrimonio, su esencia: los seres humanos $y$, por lo tanto, el efecto que esos bienes producen sobre ellos (Torregrosa y Falcón 2013).

Si asumimos que el patrimonio no comprende sólo objetos - elementos tangibles - de valor, sino también elementos inmateriales y espirituales, aceptamos que la "dimensión humana" esté muy presente en toda la conceptualización del patrimonio hasta entender que el patrimonio es la relación entre bienes y personas. Esos bienes pueden tener componentes materiales e inmateriales, incluso la mezcla de ambos. Por eso, cuando los bienes son personas, el patrimonio es la "relación" entre personas y personas, la relación más inmaterial y espiritual que existe (Fontal 2012). En este sentido lo material, inmaterial y espiritual no son "tres tipos" de patrimonio como puede desprenderse de los tratados internacionales de UNESCO, la UE o las diferentes normativas estatales en gestión de patrimonio, sino tres rasgos o dimensiones que todo elemento patrimonial contiene, invariablemente.

4 En tercer lugar, la idea de "contextualización" está presente en la propia noción de patrimonio, que es así un sustrato situado en contexto en términos no sólo geográficos o físicos, sino sociales, políticos, religiosos, filosóficos, espirituales... La idea de "continuidad", por último, está asociada a la noción de patrimonio y a su dimensión humana, en la medida en que ha de poder ser transmitido - y, por tanto, legado - de unas a otras generaciones (McCarthy 2013). En este sentido, puede representarse como un hilo que cose esa memoria común de la humanidad; hilo porque implica la posibilidad de tejer, bordar, relacionar, ampliar, conectar. Así, ese hilo de la memoria es tomado por cada generación que decidirá si deshace la pieza que le ha sido legada, si tan sólo añade algún fragmento, si deja la pieza tal y como la ha recibido, si recuperarla por su mal estado de conservación, etc. La pieza no estará terminada jamás, salvo si se destruye y, en ese caso, existen "pruebas" o huellas de la misma, ya sean escritas, fotografiadas o recreadas por diferentes medios expresivos (Valestrand 2015).

5 En esta idea, la transmisión intergeneracional constituye la garantía de continuidad de un elemento patrimonial, pero no de los valores que sobre él se proyecten, de modo que incide en la dimensión estática. En cambio, la visión dinámica sigue la siguiente lógica educativa de orden circular: transmitimos para dar a conocer, pero el conocimiento en absoluto garantiza el deseo de transmisión, que sólo puede suceder si deriva de un disfrute estético, cultural o identitario; sólo podremos disfrutar aquello que ha sido cuidado - material, inmaterial y espiritualmente - $y$, para que algo merezca ser cuidado debe tener algún valor; pero una sociedad sólo podrá valorar aquél patrimonio que respeta y será imposible que lo respete si no lo comprende; finalmente sólo comprendemos aquello que conocemos y, dependiendo de cómo accedamos a ese conocimiento, estaremos próximos a la comprensión o, por el contrario, al rechazo. Ese fino hilo de continuidad es el producto de los vínculos, un hilo que cambia con cada generación, que engorda y se estrecha, que incorpora nuevos hilos. Siempre, cada presente añade los suyos; la creación contemporánea, también. 


\section{Metodología}

6 El objetivo principal en esta investigación es indagar sobre las descripciones de los bienes más importantes del patrimonio personal y descubrir si contienen definiciones explícitas e implícitas de los diferentes tipos de vínculos patrimoniales. Para ello, realizamos un análisis de contenido, analizando los testimonios escritos de la página web "Personas y Patrimonios" (www.personasypatrimonios.com), un espacio para compartir patrimonios, desde Noviembre de 2015 a Noviembre de 2016. " "Personas y Patrimonios" es un proyecto financiado en el marco de la convocatoria de ayudas para el fomento de la cultura científica, tecnológica y de la innovación 2014 (FCT-14-9015) y en el que colabora el Laboratorio de Fotogrametría Arquitectónica de la Universidad de Valladolid. Se trata de un proyecto colectivo en el que es posible compartir los vínculos que las personas establecen con los bienes, comenzando por los más personales e íntimos. En la página puede participar cualquier persona y compartir una imagen en la que aparezca un bien de su patrimonio y, acompañando a esa imagen, un relato que le dé sentido (real o imaginario). Los demás usuarios podrán dialogar con esa imagen mediante textos e imágenes, para poder crear cadenas de vínculos compartidos.
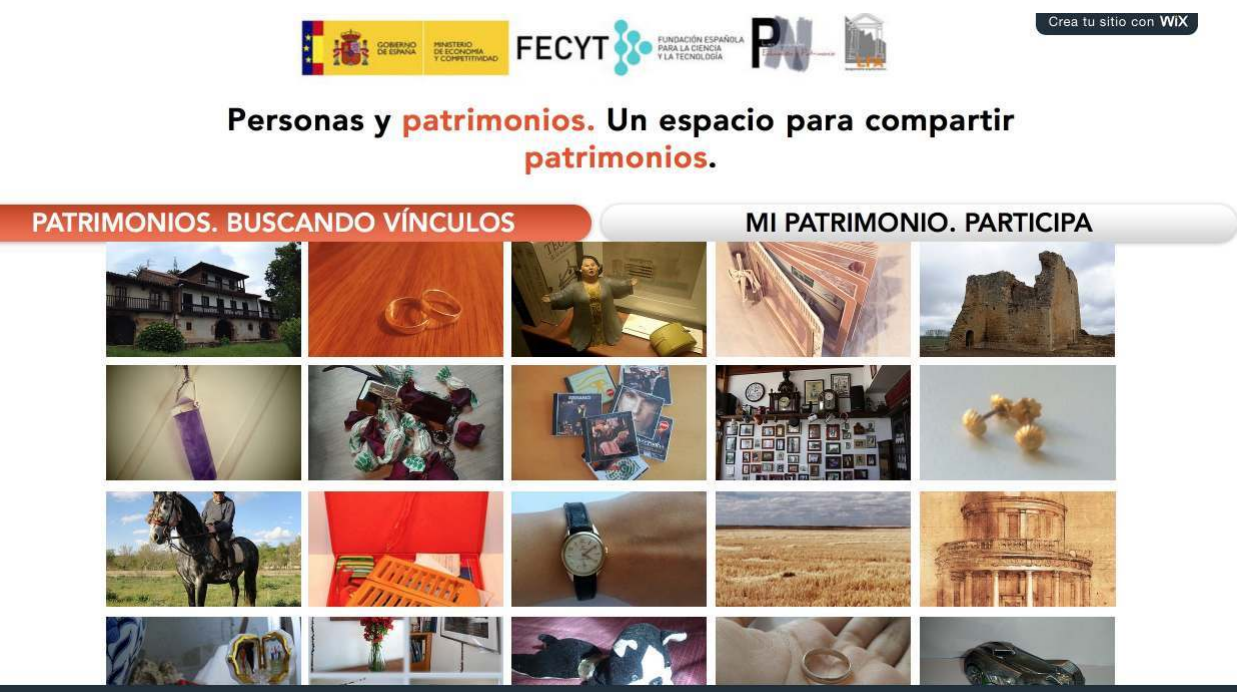

Fig. 1 - Personas y Patrimonios, un espacio para compartir patrimonios, 2016

Fotografías pertenecientes a la página web www.personasypatrimonios.com

7 Las categorías que se han utilizado son extraídas de la secuencia propuesta por Fontal (2003): conocer-comprender-valorizar-sensibilizar-preservar-disfrutar-transmitir-sociabilizaridentizar. Por tanto, el sistema de categorización es a priori deductivo de las categorías a los datos. Para la categorización y codificación se ha recurrido al uso del software Nudist*Vivo para Mac.

\section{Análisis y resultados}

Una vez categorizadas y codificadas las evidencias de nuestra muestra de 49 relatos, se analizan cada una de ellas siguiendo el orden categorial. A continuación, vamos a exponer una serie de gráficos en los que se muestran las categorías o nodos con sus respectivos fragmentos de los relatos con el fin de averiguar cuáles son aquellos recursos que 
emplean más comúnmente las personas para tratar de expresar los vínculos que tienen con un elemento patrimonial. Como se observa a través de los porcentajes en la fig. 3, el nodo de la "identización" (Gómez 2012) es el más abultado, por lo que podemos observar que tendemos a identificarnos con el bien patrimonial que pretendemos enseñar y describir, correspondiendo con la etapa final del proceso de vinculación:

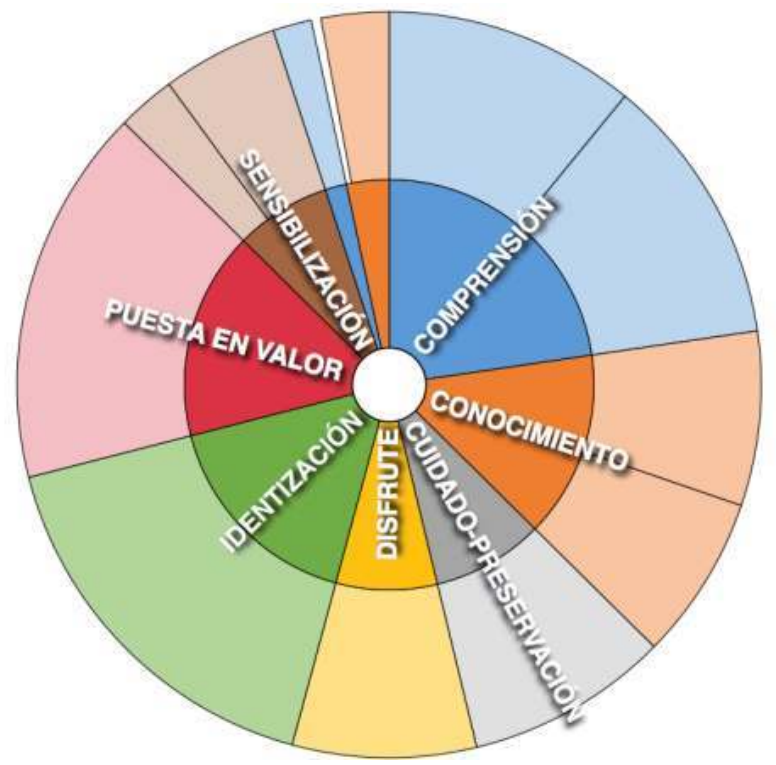

Fig. 2a - Diagrama de sectores comparando los nodos o categorías, 2017

Fuente: Inmaculada Sánchez-Macías, Jesús Cepeda y Olaia Fontal a partir de Nudist*Vivo

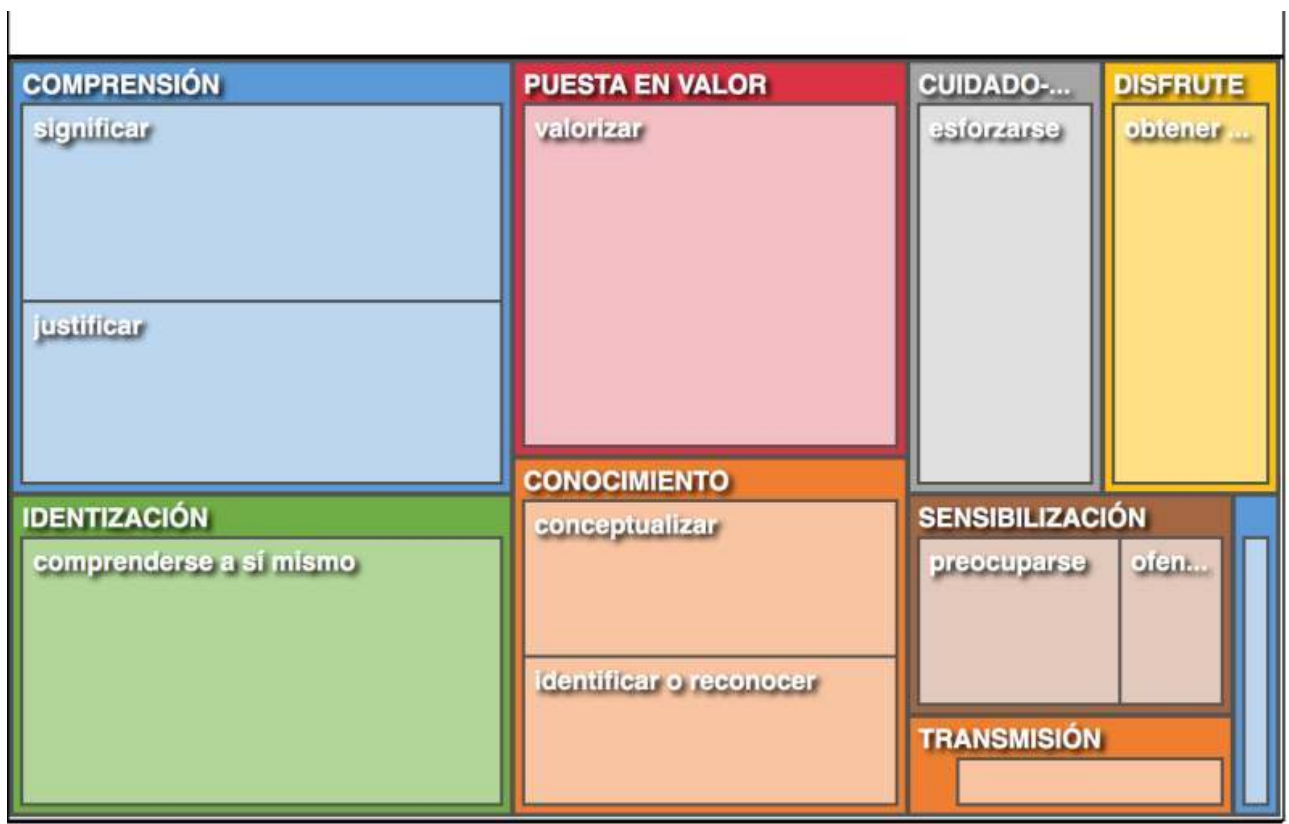

Fig. 2b - Diagrama de sectores comparando los nodos o categorías, 2017

Fuente: Inmaculada Sánchez-Macías, Jesús Cepeda y Olaia Fontal a partir de Nudist*Vivo 

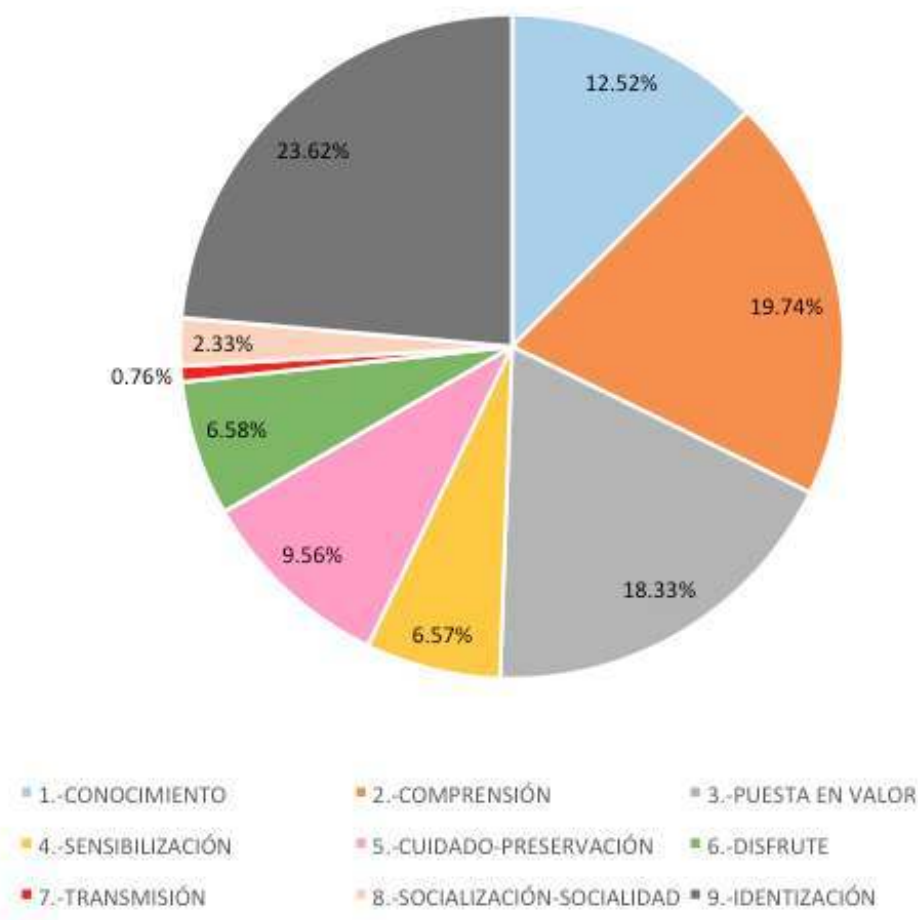

Fig. 3 - Porcentaje de fragmentos de textos por categorías, 2017

Fuente: Inmaculada Sánchez-Macías, Jesús Cepeda y Olaia Fontal

\section{Conocimiento}

9 La primera categoría con la que da comienzo el proceso de vinculación entre persona y patrimonio es el "conocimiento". Conocer es la acción más genérica que podemos realizar cuando se observa por primera vez una imagen o cuando viene a la memoria un recuerdo con el que sentimos una mínima relación afectiva y, por tanto, generamos un vínculo de conocimiento. Para conocer es necesario identificar y reconocer para, posteriormente, poder conceptualizar. De este modo, en los textos analizados se evidencian múltiples referencias que demuestran cierto conocimiento por parte del escritor hacia el patrimonio que trata de mostrarnos.

\subsection{Identificar, reconocer}

Dentro de la fase de conocimiento se halla la categoría con la que se identifican y reconocen los bienes patrimoniales. Para ello, el narrador de cada historia utiliza la descripción con la que se hace referencia al bien cultural, como se expone en los siguientes fragmentos:

A simple vista se trata de una caja insignificante. Un cofre hecho de madera, pintado a mano y con una flor morada con frutos rojos. [FAN-15-1-2016 REF 1]

11 Pero, a menudo, el escritor alude a imágenes que encuentra en su subconsciente y que le facilitan esa labor de reconocimiento, sin necesidad de ser más explícito en detalles físicos y que pueden enfriar esa relación que tiene con dicho bien:

Esencias de una infancia; el olor del eucalipto en la plazuela de mi barrio, la planta del tomate entre las manos ya melladas, la rosa añeja del cuarto señorial y esa 
esencia indescriptible a la que olían los abrazos, los besos, los consejos, los paseos, e incluso, las reprimendas. [SIL-13-11-2015 REF 1]

12 Además, se tienen en cuenta detalles muy objetivos como pueden ser localizaciones, tiempos o denominaciones que ayudan en la identificación de un objeto, de un paisaje, de una persona, etc.:

Esta sierra "La mujer muerta" es parte de mi patrimonio. Vivo en un pueblo cercano, en las faldas de la propia montaña y cuando me levanto por las mañanas es lo primero que veo. [J. $\mathrm{M}^{\mathrm{a}}-24-1-2016$ REF 1]

\subsection{Conceptualizar}

13 Conceptualizar es organizar la imagen mental que podamos tener de un recuerdo, de una experiencia, con el fin de crear una idea más firme que el mero hecho de su reconocimiento e identificación. Es la segunda subcategoría que cierra la fase de conocimiento y que complementa a la anterior.

En los siguientes fragmentos se descubren ejemplos en los que el narrador cuenta la idea que tiene del recuerdo patrimonial mucho más conceptualizada que en la fase anterior, ofreciendo más detalles que ordenan su imagen, pero utilizando el mismo recurso, la descripción:

Comencé a coleccionarlo hace cinco años ya, cuando una amiga de Estados Unidos me trajo las dos primeras piezas (...). A partir de ahí, ya sea por regalos o porque yo los he ido comprando tengo ahora mismo 30 piezas, que simbolizan algo muy importante para mí, pero lo más importante es que colecciono los símbolos de los estados de Estados Unidos que he visitado, ya que algún día en mi vida quiero visitarlos todos. [TER-15-1-2016 REF 1]

\section{Comprensión}

La segunda fase que continua tras la de "conocimiento" en la secuencia de vínculos entre personas y patrimonios es la "comprensión”. Una vez reconocido e identificado el bien cultural resulta lógico que la persona sea capaz de comprender el significado que tiene para ella, y de este modo ser capaz de justificar los motivos que le relacionan con dicho bien. Por todo esto, dividimos la fase de "comprensión" en dos subcategorías, "significar" y "justificar", que comentaremos brevemente apoyándonos en ejemplos de relatos.

\subsection{Significar}

16 Con esta categoría nos referimos a la capacidad que tiene una persona de extraer los signos más relevantes y que han formado la idea en la etapa de conocimiento acerca de un bien cultural con el que se siente vinculado de alguna manera. Para verlo de manera más clara y práctica, existen una serie de fragmentos de relatos en los cuales, una vez se ha descrito el bien cultural, el narrador profundiza más en aspectos que permiten observar la importancia que tiene para esa persona lo que trata de contar.

Este es mi patrimonio, mi vida, mis pensamientos, mi imaginación... Es el arte de dibujar... el arte de expresar lo que con palabras no puedes decir, el arte de plasmar en una simple hoja de papel lo que te dice el corazón y el alma. [NOE M-30-1-2016 REF 1] 


\subsection{Justificar}

17 Pero quedaría incompleta la comprensión sin la explicación de los motivos que justifiquen la elección del bien patrimonial por parte de la persona que relata estas historias y otorguen de sentido al propio significado:

Este lugar tiene un significado muy importante para mí: empecé yendo con catorce

años en verano, de pre-monitora en el campamento que ahí se desarrollaba.

[MAR-31-1-2016 REF 1]

18 En todos estos textos se observa la relevancia que presentan para todos los escritores aspectos de su vida que quizá para el resto de personas serían irrelevantes o cotidianos. De esta manera, el patrimonio va adquiriendo forma y valor, puesto que si no existiese una relación afectiva entre lo descrito y quién lo describe, no existiría patrimonio. Así, se enlaza con la siguiente fase que mantiene relación con ésta, la puesta en valor, ya que una vez evidenciados el significado y la justificación de la importancia del bien para la persona, el valor surgirá sólo.

\section{Puesta en valor}

19 Como se ha comentado en la etapa anterior, la comprensión del bien cultural por parte de cualquier persona es el paso previo que desemboca en la puesta en valor de dicho bien, puesto que previamente ya se le ha otorgado un significado y unos motivos por los cuáles se manifiesta una relación afectiva entre ambas partes. Poner en valor es, si utilizamos los vínculos de la fase anterior, dotar de importancia, más allá de la que pueda tener algo por el mero hecho de existir, a una cosa que previamente carecía de ella y que gracias al vínculo establecido con la persona, puede llegar a tenerla. En realidad se trata de una acción que realizamos constantemente y, muchas veces, de manera inconsciente.

\subsection{Valorizar/poner en valor}

Una vez explicado el vínculo, se puede ejemplificar con más fragmentos de relatos en los que se ponen en valor numerosos objetos, experiencias, personas que componen el patrimonio más personal de cada uno de los narradores:

Pero para mí, representan mucho más que el haber visitado el lugar del que provienen, sino que cada vez que los miro, cada uno representa las distintas aventuras, anécdotas y recuerdos que encierran de momentos felices y tristes; los lugares y sus vistas, sus costumbres y sus gentes. Sus historias y las mías. [ADR-31-1-2016 REF 1]

\section{Sensibilización}

21 Una vez identificado y reconocido el bien, comprendido su significado y puesto en valor, es inevitable hacer uso de la subjetividad más profunda de cada persona, donde las emociones empiezan a florecer cada vez más y nos preocupamos por los agentes externos "erosivos" que dañan tanto física como verbalmente nuestro bien más preciado.

\subsection{Preocuparse}

Es ahora cuando se añora la existencia del recuerdo que se trata de contar, cuando invade una necesidad inmensa de recuperar algo que se ha perdido o, todo lo contrario, cuando 
se tiene miedo de perderlo. También hay momentos en los que molesta la dejadez en la que se encuentra algo que para nosotros tiene mucho valor, porque tiene un gran significado que, en cambio, no es compartido por otras personas.

Esta persona, advirtió el brillo en mi mirada al verlos y unos segundos más tarde, tenía una tercera amatista en mi poder, la más púrpura del cestito. De esto hace ya un año aproximadamente, y cada vez que la siento en mi cuello puedo admirar su belleza y la de las dos piedras que me habían acompañado antes, cada una, perfecta a su manera. [CAR LGM-21-11-2015 REF 1]

Como nadie lo quería el castillo se caía. [JUA-20-11-2015 REF 1]

\subsection{Ofenderse, molestarse} que pueda expresar una persona, como se acaba de comentar. Pero siempre se hacen ver con un tono más elevado que al de la simple preocupación. No obstante, en los siguientes textos, apenas apreciamos diferencias con la subcategoría anterior, puesto que son sentimientos y emociones muy relacionados, que surgen recíprocamente:

El día que perdí uno de los zapatos, la tristeza y la rabia, me invadieron, ya que

había perdido parte del tesoro. [LAU-15-1-2016 REF 1]

\section{Cuidado-preservación}

\subsection{Esforzarse}

En esta categoría se puede observar cómo las evidencias escritas muestran las reacciones que los autores tienen hacia sus objetos patrimoniales, ya sean materiales o inmateriales. Se trata de proteger o resguardar a alguien o algo, intentando conservar su estado, de un daño o peligro. La palabra preservar - del latín praeservare -, nos remite a observar, prestar atención, guardar, conservar, mantener intacto. También se emplea para referirse al cuidado o integridad en muchos ámbitos, como por ejemplo dentro del arte. Por ello, se habla de la preservación del patrimonio cultural de un pueblo, de una región o de toda la humanidad, mediante la cual se salvaguarda y protege no sólo bienes muebles sino también regiones y lugares de la acción del tiempo y del hombre. Se ha hablado de la conservación patrimonial en estas definiciones de modo genérico, de manera que compete más a unos derechos sociales y normativos para conservar los bienes públicos mediante presupuestos, instituciones, técnicas y profesionales.

Ese marco descrito de profesionalidad o de esfuerzo técnico puede enmarcar nuestro trabajo concreto, como nos apunta una de las declaraciones:

[...] Yo primero protestaba por esa dura tarea que me daba tantísima pereza, pero siempre lo acababa haciendo con la mejor de mis caligrafías." [OLA 13-11-2015 REF.1] supeditado a las motivaciones, sentidos y emociones de los informantes:

En un futuro quiero llevarla a un restaurador, que la de lustrosidad por fuera y arregle el mecanismo para poder oír, por fin, la melodía que guarda en su corazón. [JIM 21-1-2016 REF 1]

En el siguiente testimonio se enlaza el esfuerzo por la integridad física del bien patrimonial con su función simbólica y emocional: 
Mi madre me los confió bajo la promesa de que los cuidaría, desde entonces los llevo puestos y no tengo ninguna intención de sustituirlos porque son mi pequeño gran tesoro. [BEA 24-11-2015 REF 1] generaciones o recopilaciones de fotografías, todo ello con intención de documentalismo y excelencia "técnica" semejante a los profesionales del sector:

Mi padre comenzó a hacernos una colección de sellos desde el año en que nacimos a cada uno de los hermanos. Cuando nos hemos ido yendo de casa mi padre nos ha ido regalando las colecciones que ha completado desde el año que nacimos para que nosotros la vayamos completando. [CAR 24-1-2016 REF 1]

En conclusión, se podría pensar que el ámbito profesional y el privado de la conservación patrimonial no son dos compartimentos estanco, puesto que la excelencia técnica del profesional no puede olvidar la función simbólica del arte que maneja; ni el espacio afectivo de lo privado puede prescindir del mayor esfuerzo técnico de preservación física de los objetos patrimoniales.

\section{Disfrute}

\subsection{Obtener placer}

Respecto a esta categoría, la sociedad contemporánea ofrece cientos de formas objetuales de obtener placer muy alejadas del ámbito de estudio de este trabajo; la propuesta vigente es hacia el objeto moderno o posmoderno, efímero, comercial, tecnológico y el discurso es que esa tipología es la que únicamente puede ofrecer placer. Por el contrario, nuestra muestra de informantes exhibe igualmente disfrute (y placer) pero conceptualizado de modo mucho más complejo. Un disfrute de momentos de amor y actos de amor:

Estaba paseando por Santillana del Mar y vi una tienda en la que había todo tipo de bisutería, entré y me quedé mirando este anillo, el más simple de todos, y mi padre me vio. Un rato más tarde llegó con él y me lo regaló, desde entonces no he vuelto a quitármelo. [CAR 30-1-2016 REF 1]

Disfrute como deseo por el objeto y cariño (sentimiento, pasión, etc.) expresado en comunidad a veces y otras veces en solitario:

Los niños de mi clase, enseguida me notaron triste y, cuando les conté lo que me había pasado, enseguida me dijeron "no te preocupes, seguro que puedes hacer otro igual" y me dieron un abrazo y un beso. [LAU 15-1-2016 REF1]

Se descubre un léxico específico del disfrute emocional que por definición es complicado expresar en el ámbito científico de investigación, pero que no puede evitar desbordarse en boca de los informantes respecto a nuestro objeto de estudio, como podemos observar en las anteriores declaraciones descritas. Se descubren más evidencias con este léxico y descripciones placenteras en las cuales los informantes extreman su vocabulario sensual:

[...] que al cerrar los ojos e inhalarlo te recrea las escenas de una plena felicidad infantil y adolescente. Donde todo parecía estar en orden, donde no existía el miedo, donde los malos momentos se resolvían con un sonidito semejante a los besos, que, sin embargo, no requería el movimiento de los labios, pero te aliviaba...

[SIL 13-11-2015 REF 1] 


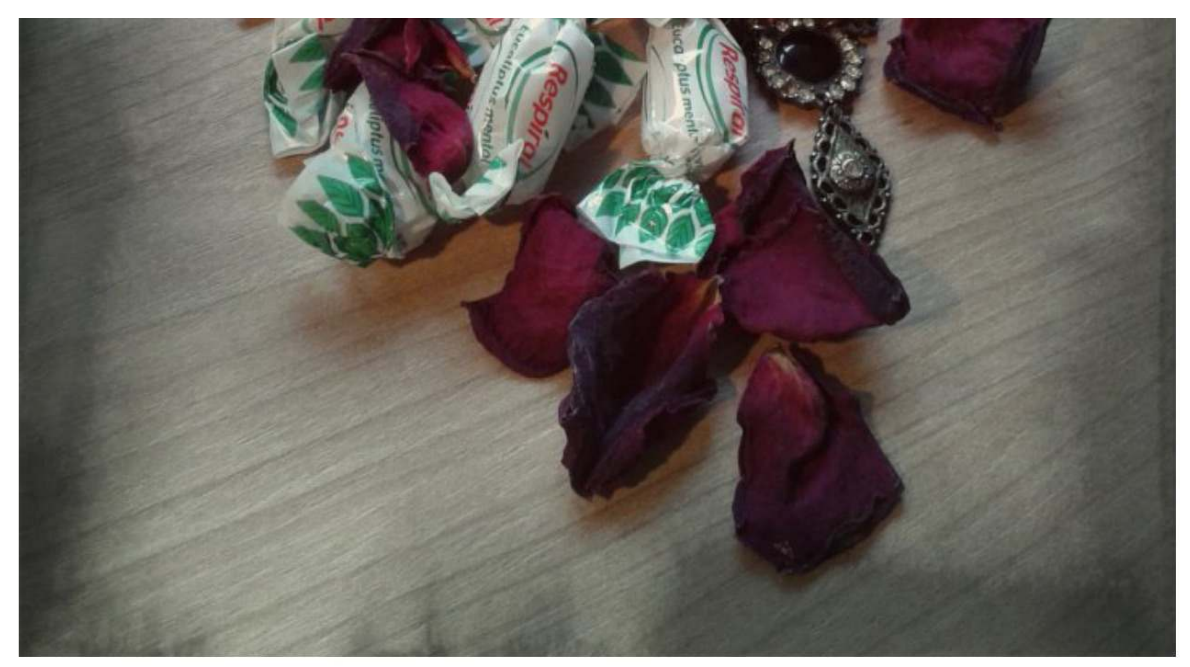

Esencias de una infancia; el olor del eucalipto en la plazuela de mi barrio, la planta del tomate entre las manos ya melladas, la rosa añeja del cuarto señorial y esa esencia indescriptible a la que olian los abrazos, los besos, los consejos, los paseos, e incluso, las reprimendas. Esas huellas impregnadas en la memoria que hacen que guardes de la manera más tierna los recuerdos de un pasado, que al cerrar los ojos e inhalarlo te recrea las escenas de una plena felicidad infantil y adolescente. Donde todo parecía estar en orden, donde no existía el miedo, donde los malos momentos se resolvian con un sonidito semejante a los besos, que sin embargo, no requería el movimiento de los labios pero te aliviaba. Te agarrabas fuerte de la mano, esa mano rugosa, cargada de experiencia, de trabajo, de cariño y de tesón que tenía el poder de la calma.

Fig. 4 - Fotografía de la página web www.personasypatrimonios.com, 2015

Fotografía realizada por Silvia

\section{Transmisión}

\subsection{Dar a conocer}

Como se ha descrito en el análisis de la categoría 5 sobre "cuidado y preservación", no hay compartimentos estanco en lo patrimonial; la memoria de las personas se enlaza con la memoria de sus ciudades y así, la transmisión del patrimonio familiar es también del patrimonio histórico y geográfico del lugar. Así se puede comprobar en los siguientes testimonios de forma explícita:

Pero además es patrimonio porque trata sobre la ciudad de Segovia, permite conocerla con profundidad y dan cuenta del interés que ha despertado la ciudad a lo largo de los años. [ANG 21-1-2016 REF 1]

En la siguiente cita se recogen dos elementos interesantes: el primero, la transmisión del patrimonio como elemento diacrónico, a través de una colección pensada para ser compuesta y formada durante varias generaciones; $y$, segundo, el uso explícito de objetos sociohistóricos (por ejemplo, la filatelia) como puente entre el patrimonio comunitario y la colección en el ámbito privado-familiar.

Mi padre comenzó a hacernos una colección de sellos desde el año en que nacimos a cada uno de los hermanos. Cuando nos hemos ido yendo de casa mi padre nos ha ido regalando las colecciones que ha completado desde el año que nacimos para que nosotros la vayamos completando... [CAR 24-1-2016 REF 1] 


\section{Socialización - socialidad}

\subsection{Incluir el bien en sus relaciones sociales}

a veces explícita - hacia los círculos concéntricos sociales: el pueblo, la ciudad, la comarca, el país...

La medalla que tiene es la Virgen de la Fuencisla que es patrona de la ciudad y quien me da nombre. Pertenezco a un grupo de bailes regionales desde pequeña. Iba a "jotas" como clase extraescolar, pero cuando me fui haciendo mayor y se me empezó a dar mejor, empecé a ir con el grupo a festivales, primero regionales y luego nacionales. [FUE 24-1-2016 REF 1]

El siguiente testimonio muestra la dimensión de trabajo colectivo de los objetos del patrimonio familiar que pasan a ser un símbolo de dicha colectividad por definición.

Para alguien puede resultar una simple colección de botes, pero, para que esto fuese posible, ha participado gran parte de mi familia durante años. A cada ciudad que vamos, esto es lo que busco, esto es lo que me ayudan a buscar. Han colaborado conmigo, ya que, si no hubiera sido por ellos, no hubiera tenido la posibilidad de conseguirlos. [NAT 1-2-2016 REF 1]

Este testimonio compendia el marco socializador de las zonas rurales con gran importancia del proceso de convivencia; y, por otro lado, el marco de valores compartidos, las tradiciones y costumbres étnicas. En estas sociedades actuales el culto por el objeto físico se diluye y ha de investigarse en relación con toda esta serie de elementos inmateriales:

Pero él no sabe que la herencia que realmente tiene valor para mí, son los recuerdos de esos veranos, son los recuerdos que sigo construyendo los sábados que salimos a montar o las romerías a las que vamos juntos con los caballos y amigos, que terminan en largas comidas en el campo. Es el amor a los animales y a la naturaleza y el respeto a nuestro origen, antepasados y a la tradición, aquello que realmente heredaré. Esa filosofía de vida, donde las cosas importantes son la familia y la gente que nos rodea, donde ayudar a los demás no es una opción, donde el compromiso es necesario y donde lo importante es ser feliz a pesar de las dificultades. [MAR 21-11-2015 REF 1]

\section{Indentización}

\subsection{Comprenderse a sí mismo}

Hay objetos patrimoniales, como las fotografías, propensos al "viaje en el tiempo", al desplazamiento diacrónico de la memoria del espectador. Éste se redefine constantemente con referencia no sólo al presente, sino al pasado, a los seres y referencias que lo habitaron. Ese viaje no es aséptico ni meramente emocional, sino completo en el sentido de "dialogar" con el pasado para seguir comprendiendo la vida y a uno mismo. Como nos muestra la evidencia, «a partir de ellas surgen nuevos recuerdos que en ocasiones parecen estar casi olvidados», aludiendo al sentido generador de la contemplación del objeto.

La memoria en ocasiones puede jugarnos malas pasadas, pero las fotografías inmortalizan esos momentos de los cuales no queremos olvidarnos, y a partir de ellas surgen nuevos recuerdos que en ocasiones parecen estar casi olvidados. A través de las fotografías tengo la posibilidad de volver a ver y acercarme a personas 
que ya no se encuentran aquí. Mientras las miró, me da la impresión de que puedo hacer retroceder el tiempo y volver a revivir esos momentos durante unos minutos, aunque sea en mi imaginación. Sin recuerdos las personas no somos nada, y para mi ésta es la mejor manera de mantenerlos y conservarlos vivos. [EVA 7-11-2016 REF 1]

\section{Eva}

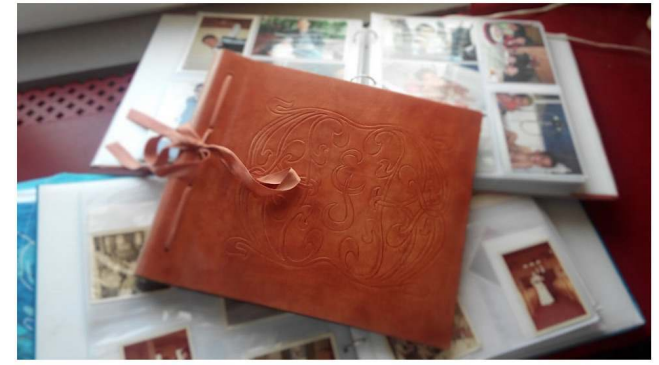

Si tuviera que salvar solamente un objeto material, si duda serian mis álbumes. En mi opinión todas las personas tenemos dos formas de mantener nuestros recuerdos: A través de la memoria y a través de las fotografías. La memoria en ocasiones puede jugarnos malas pasadas pero las fotografias inmortalizan esos momentos de

A través de las fotografías tengo la posibilidad de volver a ver y acercarme a personas que ya no se encuentran aquí. Mientras las miró, me da la impresión de que puedo hacer retroceder el tiempo y volver a revivir esos momentos durante unos minutos, aunque sea en mi imaginación.

Sin recuerdos las personas no somos nada, y para mi ésta es la mejor manera de mantenerlos y conservarlos vivos.

Noviembre 2016

Fig. 5 - Fotografía de la página web www.personasypatrimonios.com, 2016

Fotografía realizada por Eva

No obstante, hay que reconocer el componente "mítico y difuso" de ese diálogo con el pasado como indica este informante:

Siempre hay hortensias en los mazos del jardín, calas junto al regato de delante y una o dos flores en el magnolio, al alcance de la mano, cuyo frescor me devuelve a una infancia entre mítica y difusa donde me pierdo a gusto, porque no cabe otra manera de hacerlo. [PAB 13-11-2015 REF 1]

Respecto a la identidad, exponemos tres tipologías: identidad objetual, identidad emocional e identidad ética; no como categorías estancas como ya se ha mencionado, sino definiéndolas por sus rasgos dominantes.

Identidad objetual: el objeto patrimonial se mimetiza con la persona íntegramente en sus declaraciones. El informante defiende esa mímesis para sí mismo y para los demás:

Por supuesto que es algo muy importante para mí, SIEMPRE, lo llevo puesto, duerme conmigo, y una vez que conoces su historia, descubres que es algo que me define desde la primera pieza hasta la última. [TER 15-1-2016 REF 2]

En esta otra evidencia que, aunque con muchos elementos emotivos, podría llamarse de identidad objetual y teniendo el interés añadido de representar una identidad fundacional, es decir, volcada en el futuro: una nueva familia.

Para mí el patrimonio son aquellas cosas que nos definen, por eso he elegido el cuaderno de dibujos de mi hija cuando era pequeña. Tenerla a ella nos hizo configurarnos como familia y este libro, es para mí, un símbolo de esa nueva identidad, como familia y como madre. [YOL 21-1-2016 REF 1]

Identidad emocional: el objeto encierra y evoca ciertas emociones que son constitutivas de la persona en su dimensión más profunda.

Cada vez que entro en mi habitación y veo esta cajita "insignificante" y sin sentido para muchos, muchos recuerdos afloran dentro de mí junto con lo que aportó ella a mi vida. [FAN 15-1-2016 REF 2] 
de lo patrimonial en la medida que supone un referente identitario para los habitantes de la cultura en la que vivimos y puede cumplir las dimensiones clave que definen la esencia o denominador común del patrimonio. Pero también es cierto que esos nuevos valores que se proyectan sobre creaciones del pasado también van formando parte de las propias creaciones, de manera que un bien patrimonial es el conjunto de todos esos valores: los del momento de su creación, los de los diferentes momentos por los que transita y los del momento de su percepción. $\mathrm{Y}$ esto es posible por algo que ya hemos expuesto: la subjetividad, lo cambiante, lo relativo. derecho propio. El presente no puede ser un "agujero negro" en la historia, nunca lo ha sido; no puede carecer de olor y debe alterar todos los olores del pasado que recibe. Los habitantes del presente cultural debemos adquirir conciencia - y, por tanto, aceptar la responsabilidad - de nuestro papel determinante como legatarios directos de los elementos patrimoniales de nuestro tiempo, conscientes de que la primera selección será justamente la nuestra. Espacios de exposición directa de la cultura de nuestros días como museos, centros o galerías, entre otros, podrán conseguir que los públicos - entendidos en plural por su diversidad - patrimonialicen esas expresiones culturales, las hagan suyas, entiendan sus conexiones, se sientan parte de su tiempo. Además, el patrimonio de cada contexto es característico del mismo, resultado de su historia, de su espiritualidad, de su composición social, de sus actuaciones políticas, etc. 


\section{El patrimonio cultural contemporáneo: una realidad viva progresiva}

El patrimonio es una realidad viva y en constante transformación; cada época, cada sociedad legataria proyecta una serie de cambios materiales, inmateriales y espirituales sobre el patrimonio, que lo van modificando igualmente. Podríamos afirmar, en este sentido, que el patrimonio arrastra o soporta un "historial" de cambios que no hacen sino "modularlo" (en un espectro que abarca desde pequeños cambios hasta profundas modificaciones). Por eso, podemos diferenciar dos grandes momentos en la vida de un elemento cultural: su origen o gestación y su “(auto)construcción” (Riechmann 2015).

Por lo tanto, el patrimonio cultural presenta siempre un origen que es referido al surgimiento del ente cultural y otro origen, que no siempre sucede (dado que existe una necesaria selección de entes culturales), y que se refiere a su consideración por la ciencia, al origen de su estudio. La distancia entre ambos dependerá de las concepciones científicas que se interpongan entre ellos y de los nuevos usos e interpretaciones; dependerá, en definitiva, del cambio cultural al que sea sometido ese patrimonio cultural. A partir de esta diferencia podemos plantearnos la situación presente del patrimonio cultural. De manera que, una vez asumimos la necesidad de estudiar la cultura del pasado para que pueda existir en el presente, más allá de sus huellas (bienes materiales, valores...), debemos preguntarnos acerca de nuestra responsabilidad con la cultura del presente $\mathrm{y}$, siguiendo estos planteamientos, por las huellas que está dejando nuestro presente cultural en la cultura heredada, y que serán transmitidas al futuro formando parte de ese elemento cultural. En este caso también se hace necesario situar los márgenes entre pasado y presente para poder diferenciar la cultura contemporánea de la cultura histórica. Esta delimitación puede ser de muchos tipos: cronológica, económica, política, etc. Pero, de todas ellas, existe una demarcación que engloba a todas las demás, por contenerlas; nos referimos a una delimitación basada en el paradigma de pensamiento. De forma que el cambio en las estructuras de pensamiento puede concebirse como el causante de un cambio en el comportamiento y en las circunstancias socio-políticas de un contexto cultural (Riechmann 2015). Así, el patrimonio cultural se convierte en un mecanismo que reacciona a partir de los esquemas de pensamiento de las sociedades.

50 El presente no es un puente del pasado al futuro cuya única función es dejar en las mismas condiciones lo que recibe; sería la primera vez en la historia que esto sucedería. Tampoco es un agujero negro, porque existe una inmensa producción cultural característica, específica, definitoria del "hoy", del "ahora". Esto supone que el presente no va a legar el patrimonio en las mismas condiciones en que lo recibió y que, además, debe aportar su propia producción cultural; va a ampliar sustancialmente la pieza a tejerremanera. Es decir, el presente va a generar un cambio cualitativo y cuantitativo en el "hilo de la memoria".

51 Pese a todas las sustancias aromáticas - incluido el alma del perfume - descritas, lo primero que percibimos en "lo patrimonial" son ciertos aromas de salida que, por otra parte, no podrían entenderse sin esas esencias básicas. Así pues, aunque lo patrimonial al principio huela a historia o a monumento, no sólo es eso. Lo histórico parece ser un elemento de peso, de manera que el paso del tiempo parece proporcional al peso patrimonial; esto es, como poco, injusto. En absoluto es directamente proporcional la 
antigüedad de un bien con su potencial como referente identitario; podríamos pensar que, en todo caso, debería ser a la inversa, es decir, cuanto más próximo en el tiempo, más referentes identitarios encontraremos en determinado bien. Esto tampoco es exacto, mejor es suponer que los referentes identitarios son muy diversos: unos históricos, otros ideológicos, otros simbólicos, otros emocionales, otros contextuales... Por otra parte, lo monumental es sólo una parte - y, además, muy pequeña si tomamos en consideración todo lo potencialmente patrimonial del patrimonio. La relación de los bienes patrimoniales con las personas no viene necesariamente marcada por el tamaño y dimensiones de esos bienes, ni tampoco por su monumentalidad o grandiosidad. Quizá ciertos usos del patrimonio como el turístico hayan amplificado esos potenciales identitarios en la misma proporción que el potencial turístico de esos bienes, pero, aunque la turística sea una mirada esencial en nuestros días, no es la única y, desde luego, no es la más importante. En realidad, ninguna lo es, todas se necesitan y complementan unas a otras, pero, por eso mismo, hemos de reivindicar la mirada educativa, con sus intereses específicos y claves en la conexión de los bienes patrimoniales con las personas.

Finalmente, lo material es sólo la parte visible, tangible, de los ingredientes patrimoniales, pero no podemos ni debemos olvidar que hay otros ingredientes inmateriales tanto o más importantes. Pensemos, para entender esto, en lo que supone para una persona perder sus objetos valiosos, como por ejemplo ese cajón de recuerdos materiales que muchos atesoramos: una postal, una entrada a un concierto, una servilleta usada del día en el que conocimos a nuestra pareja... Desde luego, perder todo eso supone perder el vestigio material de un hecho, situación o persona, pero aún nos queda el recuerdo de lo que sucedió. A partir de estos ejemplos, podemos reconocer cómo nuestro patrimonio inmaterial tiene un grandísimo valor, quizá mayor que el patrimonio inmaterial, pero, en todo caso, clave. Y, por extensión, la dimensión inmaterial de "lo patrimonial" es, como poco, fundamental (Jacobi y Luckerhoff 2009).

Así pues, lo patrimonial no sólo adjetiva a la historia, monumentos y bienes materiales; hay que descubrir toda la estructura del perfume, entenderlo en su complejidad y, sobre todo, no usar lo patrimonial para ocultar otros olores o pensando sólo en el efecto embriagador que produce su aroma. El educador que pretende trabajar para lo patrimonial, sabe que es sólo en pequeñas dosis y siempre en conjunción con otros aromas, que se puede emplear esa fragancia (Falcón, Fontal y Torregrosa 2015).

\section{BIBLIOGRAFIA}

Brantefors, Lotta. 2015. "Between Culture and Cultural Heritage: Curriculum Historical Preconditions as Constitutive for Cultural Relations - The Swedish Case." Pedagogy, Culture \& Society 23 (2): 301-322.

Falcon, Roberto, Olaia Fontal, y Apolline Torregrosa. 2015. "Le Patrimoine comme don du Temps." Sociétés (3): 115-124. 
Fontal, Olaia. 2003. La Educación Patrimonial. Teoría y Práctica en el Aula, el Museo e Internet. Gijón: Ediciones Trea.

Fontal, Olaia. 2008. “La Importancia de la Dimensión Humana en la Didáctica del Patrimonio.” La Comunicación Global del Patrimonio Cultural, coord. Santos M. Mateos Rusillo, 79-110. Gijón: Ediciones Trea.

Fontal, Olaia. 2012. "Patrimonio y Educación: Una Relación por Consolidar." Aula de Innovación Educativa (208): 10-13.

Fontal, Olaia. 2013. "Estirando hasta dar la Vuelta al Concepto de Patrimonio." In La Educación Patrimonial: Del Patrimonio a las Personas, 9-22. Gijón: Ediciones Trea.

Gómez, Carmen. 2012. “Identización: la Construcción Discursiva del Individuo.” Arte, Individuo y Sociedad 24 (1): 21-37.

Jacobi, Daniel, y Jason Luckerhoff. 2009. "Public et Non-public du Patrimoine Culturel: Deux Enquêtes sur les Manifestations Différenciées de l'intérêt et du Désintérêt.” Loisir et Société/Society and Leisure 32 (1): 99-121.

McCarthy, Eunice. 2013. “The Dynamics of Culture, Innovation and Organizational Change: A Nano-psychology Future Perspective of the Psycho-social and Cultural Underpinnings of Innovation and Technology." AI \& Society 28 (4): 471-482.

Riechmann, Jorge. 2015. Autoconstrucción: La Transformación Cultural que Necesitamos. Madrid: Catarata.

Torregrosa, Apolline, y Roberto Falcón. 2013. “Patrimonios Instintivos.” In Patrimonios Migrantes, coords. Ricard Huerta, y Román de la Calle, 125-132. Valencia: Universitat de València.

Valestrand, Halldis Elina. 2015. "Text and Object: The Bus Shelter that Became Cultural Heritage." International Journal of Heritage Studies 21 (1): 81-98.

\section{NOTAS}

1. Esta página web ha sido realizada como acción de transferencia del conocimiento científico a la sociedad en el marco del proyecto financiado por la Fundación Española para la Ciencia y la Tecnologia (FECYT)/MINECO (Ministerio de Economía, Industria y Competitividad) con referencia FCT-14-9515, así como a los resultados de la investigación EDU2015-65716-C2-1-R, financiada por el MINECO y Fondos Feder.

\section{RESUMOS}

En esta investigación se realiza un análisis de contenido de una página web que custodia relatos y fotografías sobre el patrimonio de las personas que en ella intervienen (www.personasypatrimonios.com). Como un fino perfume el patrimonio va impregnando la relación de individuos y grupos con elementos materiales, inmateriales y espirituales. Se cuida aquello que se conoce; se valora aquello que se comprende y que nos hace comprendernos a 
nosotros mismos. Lo patrimonial al principio huele a historia o a monumento; no sólo es eso, falta el componente espiritual del perfume. En nuestro estudio reivindicamos la mirada educativa, con sus intereses específicos y claves en la conexión de los bienes patrimoniales con las personas.

In this research a content analysis is carried out concerning a participatory web page that keeps stories and photographs about people's personal heritage (www.personasypatrimonios.com). As a fine perfume, heritage permeates the relationship of individuals and groups with tangible, intangible and spiritual elements. One only takes care of what is known; one value what one can understand and which makes us understand ourselves. Heritage at first smells suggests history or monument; but is not only that, lacking the spiritual elements of the perfume. In our study we claim an educational view, with its specific interests and keys connecting heritage assets with people.

\section{ÍNDICE}

Keywords: heritage education, artistic education, personal heritage, cultural heritage, patrimonialization

Palabras claves: educación patrimonial, educación artística, patrimonio personal, patrimonio cultural, patrimonialización

\section{AUTORES}

\section{OLAIA FONTAL MERILLAS}

Licenciada en Bellas Artes por la Universidad del País Vasco/Euskal Herriko Unibertsitatea, licenciada en Historia del Arte y doctora en Ciencias de la Educación por la Universidad de Oviedo. Es profesora titular en la Universidad de Valladolid en Educación Artística. Actualmente dirige el Observatorio de Educación Patrimonial en España (OEPE), una sucesión de tres proyectos de I+D+i, y es co-coordinadora del Plan Nacional de Educación Patrimonial en España.

Departamento de Didáctica de la Expresión Musical, Plástica y Corporal, Facultad de Educación y Trabajo Social de la Universidad de Valladolid, Paseo de Belén, 1, 47011, Valladolid, España, olaia.fontal@uva.es

\section{INMACULADA SÁNCHEZ-MACÍAS}

Psicóloga, graduada en Educación Primaria en la mención generalista, máster en Investigación aplicada a la Educación (Universidad de Valladolid) y cursando en la actualidad un máster en Neuropsicología y Educación (UniR - Universidad Internacional de la Rioja). Contratada predoctoral PIF (Pofesor Investigador en Formación) por la Universidad de Valladolid a través de un proyecto de la Junta de Castilla y León vinculado a: “Educación Patrimonial en España: Consolidación, Evaluación de Programas e Internacionalización del Observatorio de Educación Patrimonial en España" (OEPE). Realiza su tesis doctoral en torno a la educación patrimonial, centrándose en la evaluación de programas educativos en Castilla y León. Departamento de Didáctica de la Expresión Musical, Plástica y Corporal, Facultad de Educación y Trabajo Social de la Universidad de Valladolid, Paseo de Belén, 1, 47011, Valladolid, España, España, inmasanma@gmail.com 


\section{JESÚS CEPEDA ORTEGA}

Graduado en Educación Primaria y máster en Economía de la Cultura y Gestión Cultural por la Universidad de Valladolid. Actualmente se encuentra realizando el doctorado en Investigación Transdisciplinar en Educación en la misma universidad bajo la dirección de Olaia Fontal Merillas. Colabora en el Observatorio de Educación Patrimonial en España (OEPE) y en la iniciativa "Duero Douro Patrimonio para el Desarrollo". Su principal línea de investigación se centra en la búsqueda de relaciones identitarias entre las personas y el patrimonio, con el fin de involucrar a toda la sociedad en la construcción de su memoria a partir de dicho patrimonio.

Departamento de Didáctica de la Expresión Musical, Plástica y Corporal, Facultad de Educación y Trabajo Social de la Universidad de Valladolid, Paseo de Belén, 1, 47011, Valladolid, España, pechu.cepeda@gmail.com 